\title{
Tuberous sclerosis complex for the pulmonologist
}

\author{
Yasmine Rebaine ${ }^{1,2,3,8}$, Mouhamad Nasser $\mathbb{1}^{1,8}$, Barbara Girerd ${ }^{4,5,6}$, Caroline Leroux ${ }^{7}$ and \\ Vincent Cottin (10) 1,7
}

\author{
Number 8 in the Series "Rare genetic interstitial lung diseases" \\ Edited by Bruno Crestani and Raphaël Borie
}

\begin{abstract}
${ }^{1}$ Dept of Respiratory Medicine, National Reference Coordinating Centre for Rare Pulmonary Diseases, Louis Pradel Hospital, Hospices Civils de Lyon, Lyon, France. ${ }^{2}$ Division of Pulmonology, Dept of Medicine, Hôpital Charles-LeMoyne, Montréal, QC, Canada. ${ }^{3}$ Faculté de Médecine et des Sciences de la Santé, Université de Sherbrooke, Sherbrooke, QC, Canada. ${ }^{4}$ Université Paris-Saclay, Faculté de Médecine, Le Kremlin-Bicêtre, France. ${ }^{5}$ AP-HP, Centre de Référence de l'Hypertension Pulmonaire, Service de Pneumologie et Soins Intensifs Respiratoires, Hôpital Bicêtre, Le Kremlin-Bicêtre, France. ${ }^{6}$ INSERM UMR_S 999, Hôpital Marie Lannelongue, Le Plessis Robinson, France. ${ }^{7}$ Université Claude Bernard Lyon 1, Université de Lyon, INRAE, UMR754, Member of ERN-LUNG, RespiFil, OrphaLung, Lyon, France. ${ }^{8}$ Both authors contributed equally.
\end{abstract}

Corresponding author: Vincent Cottin (vincent.cottin@chu-lyon.fr)

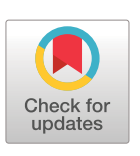

This version is distributed under the terms of the Creative Commons Attribution Non-Commercial Licence 4.0. For commercial reproduction rights and permissions contact permissions@ersnet.org

Received: 28 Oct 2020 Accepted: 20 Jan 2021

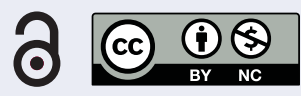

Shareable abstract (@ERSpublications)

Tuberous sclerosis complex is associated with diverse pulmonary manifestations including LAM, multiple micronodular pneumocyte hyperplasia and chylous effusions. LAM occurs in $30-40 \%$ of adult females with tuberous sclerosis complex. https://bit.ly/3iLqZ08

Cite this article as: Rebaine $\mathrm{Y}$, Nasser M, Girerd B, et al. Tuberous sclerosis complex for the pulmonologist. Eur Respir Rev 2021; 30: 200348 [DOI: 10.1183/16000617.0348-2020].

\section{Abstract}

Tuberous sclerosis complex (TSC) is a rare multisystem genetic disorder affecting almost all organs with no sex predominance. TSC has an autosomal-dominant inheritance and is caused by a heterozygous mutation in either the TSC1 or TSC2 gene leading to hyperactivation of the mammalian target of rapamycin (mTOR). TSC is associated with several pulmonary manifestations including lymphangioleiomyomatosis (LAM), multifocal micronodular pneumocyte hyperplasia (MMPH) and chylous effusions. LAM is a multisystem disorder characterised by cystic destruction of lung parenchyma, and may occur in either the setting of TSC (TSC-LAM) or sporadically (S-LAM). LAM occurs in 30-40\% of adult females with TSC at childbearing age and is considered a nonmalignant metastatic neoplasm of unknown origin. TSC-LAM is generally milder and, unlike S-LAM, may occur in males. It manifests as multiple, bilateral, diffuse and thin-walled cysts with normal intervening lung parenchyma on chest computed tomography. LAM is complicated by spontaneous pneumothoraces in up to $70 \%$ of patients, with a high recurrence rate. mTOR inhibitors are the treatment of choice for LAM with moderately impaired lung function or chylous effusion. MMPH, manifesting as multiple solid and ground-glass nodules on high-resolution computed tomography, is usually harmless with no need for treatment.

Introduction

Tuberous sclerosis complex (TSC) is a rare multisystem genetic disorder that can potentially affect all organs. TSC is the second most frequent phakomatosis after neurofibromatosis type I. During fetal life, it results in dysfunction of cell differentiation, proliferation and migration leading to various clinical manifestations that may be present at birth or manifest themselves during childhood or adulthood [1].

The first case of TSC may have been described in 1835 by a French dermatologist named Pierre François Olive Rayer who reported facial angiofibromas, calling them "facial vegetations" at that time. In 1862, the German pathologist, Friedrich Daniel von Recklinghausen reported cardiac rhabdomyomas and cortical tubers in a child. The French eponymous term "sclérose tubéreuse de Bourneville" was then coined after the French neurologist Désiré-Magloire Bourneville, who first described cortical tubers. Over the years, 
physicians from different specialities contributed to the accumulated knowledge of what we know today by the term TSC, first used in 1942 by Sylvan Moolten [2].

TSC is characterised by hamartomas in different organs including the brain, lungs, skin, kidneys, heart and eyes. However, manifestations are not universal and usually follow an age-related expression pattern; some manifestations may be obvious at birth (for example, some of the skin lesions), while others do not appear until adulthood, such as renal angiomyolipomas (rAMLs) and lymphangioleiomyomatosis (LAM). As single organ manifestations may vary from one patient to another, they often remain undiagnosed until TSC is identified. Interplay and coordination of physicians from different specialties are necessary in all cases, hence the need for multidisciplinary discussion [3].

TSC and LAM: the success of registry-based clinical research

A rare disease is defined, from an epidemiological and regulatory perspective, as any condition determined to be of low prevalence or number of cases. In the European Union, this is defined as not more than five affected persons per 10000 [4], while in the United States it is defined as <200000 patients affected, in Japan as <50000 and in Australia <2000 [5]. Low prevalence, scarcity of knowledge and phenotype heterogeneity have restricted research into rare diseases, including both TSC and LAM. Registries of rare diseases were implemented to describe the natural history and outcomes of such diseases, to support research and to establish a database for evaluating drugs and other therapies; in addition, these seek to connect patients, families and clinicians [6].

The Groupe d’Étude et de Recherche sur les Maladies “Orpheline” Pulmonaires (GERM“O”P) was founded in 1993 by Jean-François Cordier. It served as a French registry for rare pulmonary diseases and is considered to be the first registry for LAM [7]. Its name was changed recently to "OrphaLung", standing for orphan lung diseases. Over the years, registries have made possible retrospective studies of clinical and radiological manifestations [8], epidemiological studies [7], descriptions of the natural course of disease [8, 9] and the assessment of specific questions such as pregnancy in patients with LAM [10]. Furthermore, some progress has been made through retrospective surveys of members of LAM patient associations, such as the impact of air travel on the risk of pneumothorax [11]. In addition, other national registries and foundations have been set up, leading to the Multicenter International Lymphangioleiomyomatosis Efficacy of Sirolimus (MILES) trial in 2011, in which the LAM Foundation was instrumental [12].

For TSC, the "TuberOus SClerosis registry to increase disease Awareness" (TOSCA) was established in 2014 as the first international disease registry with the specific aim to gather clinical data and address knowledge gaps in the natural history and management of TSC. It comprises a core section, including diagnostic characteristics, and a "petal projects" section, exploring and focusing on specific disease manifestations (e.g. epilepsy, renal and pulmonary features, genetics) [13, 14]. For example, using the TOSCA registry data, JANSEN et al. [15] evaluated the characteristics of subependymal giant cell astrocytoma (SEGA) in patients with TSC, and observed that they also occur in adults. NABBout et al. [16] assessed the burden of epilepsies associated with TSC. KIngswood et al. [17] studied the clinical characteristics of rAMLs in patients with TSC, and described a higher frequency in females and in patients with TSC2 mutations.

\section{Epidemiology}

The prevalence of TSC is estimated to be one case per 6-10000 live births (or 1:25000 population) [18-20], with no difference across ethnic groups or sex predominance. Prevalence is age-dependent, prevailing in the young: 1:15000 in children aged $<5$ years, 1:20000 in individuals aged $<30$ years and 1:25-29000 in those aged $<65$ years [21].

While approximately $40-50 \%$ of female patients with TSC have cystic lung changes suggestive of LAM on systematic computed tomography (CT) of the chest [22-24], only a minority ( 10\%) have symptomatic LAM; not all cystic lung lesions in TSC patients are due to LAM [25].

While LAM is the main pulmonary manifestation of TSC, it may also occur sporadically (S-LAM). The prevalence of S-LAM, estimated to be between 1:100000 and 1:400 000 of the general population [26, 27], is theoretically lower than TSC-LAM; however, S-LAM is more common than TSC-LAM in the American registry [28]. This discrepancy may reflect a milder presentation of TSC-LAM, frequently diagnosed at a pre-clinical stage through systematic screening; indeed, most LAM patients requiring medical intervention have the sporadic form of the disease [29]. 
The probability of developing LAM in females with TSC increases with age until the menopause. In a retrospective study of 101 female patients with TSC aged $>15$ years, the frequency of LAM increased by $8 \%$ every year; LAM was present in $27 \%$ of patients aged $<21$ years, and in $81 \%$ of those aged $>40$ years [23]. TSC-LAM is diagnosed at a younger age ( $<35$ years), probably due to active screening. The mean age at presentation of S-LAM is 35 years [28, 30, 31] but nearly $10 \%$ of the cases are diagnosed after menopause [30]. Of note, LAM is the inaugural event in $28 \%$ of TSC patients [32].

Although LAM is classically considered a disease of females of childbearing age, it may, rarely, affect males with TSC, unlike S-LAM which occurs exclusively in females. Systematic CT screening studies in adult males with TSC using chest and lung bases of abdominal CT found cystic lung disease in 10-38\% of the subjects, although virtually none of them had clinical pulmonary manifestations [33-35]. In contrast, multifocal micronodular pneumocyte hyperplasia (MMPH), another pulmonary manifestation of TSC, occurs with no sex preference.

\section{Genetics and pathophysiology}

\section{Genes and rare variants}

TSC is an autosomal dominant disorder caused by heterozygous pathogenic variants in either the TSC1 (chromosome 9q34) or the TSC2 (chromosome 16p13) gene [36], coding respectively for hamartin and tuberin. These pathogenic variants cause constitutive activation of the mammalian target of rapamycin (mTOR) pathway, with consequent dysregulation of cell growth [37]. Of note, two-thirds of cases are caused by de novo pathogenic mutations [2, 38].

In 2012, the identification of a pathogenic mutation was incorporated into the international criteria for the diagnosis of TSC [1]. Since then, molecular testing for TSC1 and TSC2 mutations has become more widely available worldwide, thereby facilitating diagnostic, screening and counselling strategies. Only a small number of pathogenic variants are frequently found in affected individuals, thus making genotypephenotype correlation difficult. The Leiden Open Variation Database (LOVD) is a free and regularly updated web-based open-source database founded by the Leiden University Medical Centre in the Netherlands, which hosts many of the known TSC1 and TSC2 variants together with their assigned significance (benign, pathogenic or unknown significance) (https://databases.lovd.nl/shared/genes?search_ name=tuberous\%20sclerosis). It enables physicians and geneticists to interpret the results of the genetic studies in patients with TSC. LVOD catalogued 11866 variants with 1121 unique variants for TSC1 and 3251 unique variants for TSC2. Penetrance is almost complete. Mutations within TSC1 are predominantly small truncating nonsense and insertion or deletion mutations, whereas TSC2 mutations are more frequently missense mutations and large rearrangements [39]. TSC manifestations tend to be less severe, especially in the brain, kidney and lung [40]. However, variability exists in disease expression, even among family members carrying the same mutation.

Pathogenic variants can be found in TSC2 in 70\% of patients with a clinical diagnosis of TSC, and in TSC1 in 10\%; the remaining $20 \%$ of patients have no mutation identified or carry a variant of unknown significance [41, 42]. However, recent technologies such as next-generation sequencing and RNA-based approaches have identified somatic mosaicism or intronic splicing variants affecting TSC1 or TSC2 [39]. It is therefore unlikely that a third gene is involved.

\section{Impact of mutations on cell signalling}

TSC1 and TSC2 are tumour-suppressor genes. A pathogenic mutation that results in loss of heterozygosity $(\mathrm{LOH})$ disables the inhibitory function of the gene and leads to hamartoma formation [43, 44] through constitutive activation of the mTOR pathway. Hamartoma development in TSC follows Knudson's two-hit tumour-suppressor gene model. After inheriting a pathogenic germline variant in one of the TSC genes, a somatic mutation inactivates the remaining wild-type allele [45] and results in $\mathrm{LOH}$, causing angiofibromas, LAM, AMLs and renal cell carcinoma. In contrast, S-LAM and sporadic AMLs are caused by somatic first-hit and second-hit mutations inactivating each wild-type allele of TSC2.

Hamartin and tuberin (encoded by TSC1 and TSC2, respectively), together with a third protein encoded by the TBC1D7 gene, form a heterotrimeric complex called the TSC protein complex [37]. This is the main negative regulator of Ras homologue enriched in brain (RHEB), itself an activator of mTOR complex-1 (mTORC1) [46], a protein complex mainly composed of mTOR [47] and regulatory-associated protein of mTOR (RAPTOR). Activation of the mTORC1 complex is implicated in extensive metabolic reprogramming, including stimulation of nucleotide synthesis, protein translation, lipid synthesis, angiogenesis, lymphangiogenesis and cell invasion, as well as downregulation of autophagy and apoptosis. This "canonical” RHEB-mTORC1 signalling pathway is hyperactivated in patients with TSC carrying 
inactivating mutations of TSC1 or TSC2 and can be targeted by rapamycin and other mTOR inhibitors. In addition, putative "noncanonical" signalling pathways may be involved in TSC, which may be independent of TSC2, mTORC1 or RHEB [39].

\section{From TSC to LAM}

LAM is considered to be caused by the proliferation of abnormal LAM cells, found profusely in the lungs, but also in the lymph nodes, blood, uterus and chylous fluid. Morphologically, LAM cells are nearly identical to AML cells and share some characteristics with smooth-muscle cells.

LAM cells are characterised by biallelic inactivating mutations of either TSC1 or TSC2; in TSC-LAM, one mutation is considered germinal and the other somatic, whereas in S-LAM both mutations are somatic. Hyperactivation of the RHEB-mTORC1 signalling pathway is responsible for mTOR-dependent cell proliferation and potentially for cell migration [48]. LAM cells produce lymphangiogenic growth factors (vascular endothelial growth factor (VEGF)-C and -D) and growth factor receptors (VEGFR-2 and VEGFR-3). LAM cells express particularly VEGFR-3 [49], and lymphatic endothelial cells express VEGFR-3 and VEGFR-2 [50]. These agents are thought to promote lymphatic endothelial cell recruitment and budding of LAM cell clusters into the lymphatic lumen up to the pulmonary microvasculature, and then contribute to the destruction of the lung parenchyma and chaotic remodelling called "frustrated lymphangiogenesis" (figure 1) [25, 51, 52]. It has been demonstrated that greater lymphatic activity is associated with more severe disease as measured by the LAM histologic score [53]. LAM, either sporadic or associated with TSC, is therefore considered a low-grade, metastasising nonmalignant neoplasm of unknown origin [54], with similar mutations found in LAM and AML cells [55]. This theory would explain how LAM can recur after lung transplantation. Of note, TSC mutations are found only in a proportion of patients with S-LAM [56], although this may be due to mosaicism or technical limitations.

\section{Origin of LAM cells}

The origin of LAM cells remains elusive. Although different theories have been proposed (uterus, AML, ovary, neural crest), there is accumulating evidence suggesting that they may originate from the uterus. The greater incidence of LAM in females of reproductive age suggests a putative role for sex hormones in disease pathogenesis [57]. Menses influence patient symptoms and disease activity slows after menopause [9, 58, 59]. Moreover, uterine leiomyomas share some characteristics with LAM cells with regards to oestrogen and progesterone receptor expression [60], and when metastasising to the lungs they cause cystic lesions, although distinct from those seen in LAM [61]. Furthermore, LAM cells can be found in the uterus. Experimental inactivation of TSC2 in uterine cells in mice causes myometrial tumours in the lungs [62]. Recently, Guo et al. [55], using single-cell transcriptomic analysis, demonstrated the existence of unique mesenchymal cells, termed LAM-core cells, which carried similar gene mutations and gene expression within lung and uterine LAM lesions in patients with S-LAM, with close similarity to myometrial and stromal cells from normal human and mouse uteri. This observation strongly supports the theory of the uterus as a source of LAM cells in the lung. Although these findings are compelling, another source must coexist to explain TSC-LAM in males.

\section{Histology}

According to the World Health Organization (WHO) classification of lung tumours [63], LAM is considered a PEComatous tumour arising from perivascular epithelioid cells. It consists of a proliferation of plump spindle-shaped cells with typically pale eosinophilic cytoplasm called LAM cells, which carry TSC1 or TSC2 gene mutation. These cells are usually present in the pulmonary interstitium along the blood and lymphatic vessels of the lung and along the axial lymphatics of the thorax and abdomen. There are two types of LAM cells within the lungs [64]. Small spindle-shaped cells that are likely to react with antiproliferation cell nuclear antigen antibodies, and epithelioid-like cells with abundant cytoplasm. The latter react with HMB-45, a monoclonal antibody that detects a pre-melanosomal protein called gp100. Although the gp100 HMB-45 staining is classically used for the diagnosis of LAM, tyrosinase-related protein (TRP-1) is more widely expressed and could be more sensitive [65]. Both small spindle-shaped cells and epithelioid-like cells react with antibodies against smooth-muscle cell-specific antigens (e.g. $\alpha$-actin, desmin and vimentin) [66]. The destruction of elastic fibres and collagen in the basal membrane of LAM cells mediated by the secretion of matrix metalloproteinases (-2 and -9) results in cyst formation [67, 68]. Sex hormone receptors are invariably present in LAM cells [69, 70]. Interestingly, the smooth muscle cells from rAMLs have identical structure and immunohistochemical profile as LAM cells [71].

\section{Clinical manifestations}

Patients with TSC present with a broad spectrum of clinical manifestations that may vary from absent or mild symptoms, to severe and debilitating disease with multiple organ involvement (figure 2). Clinical 


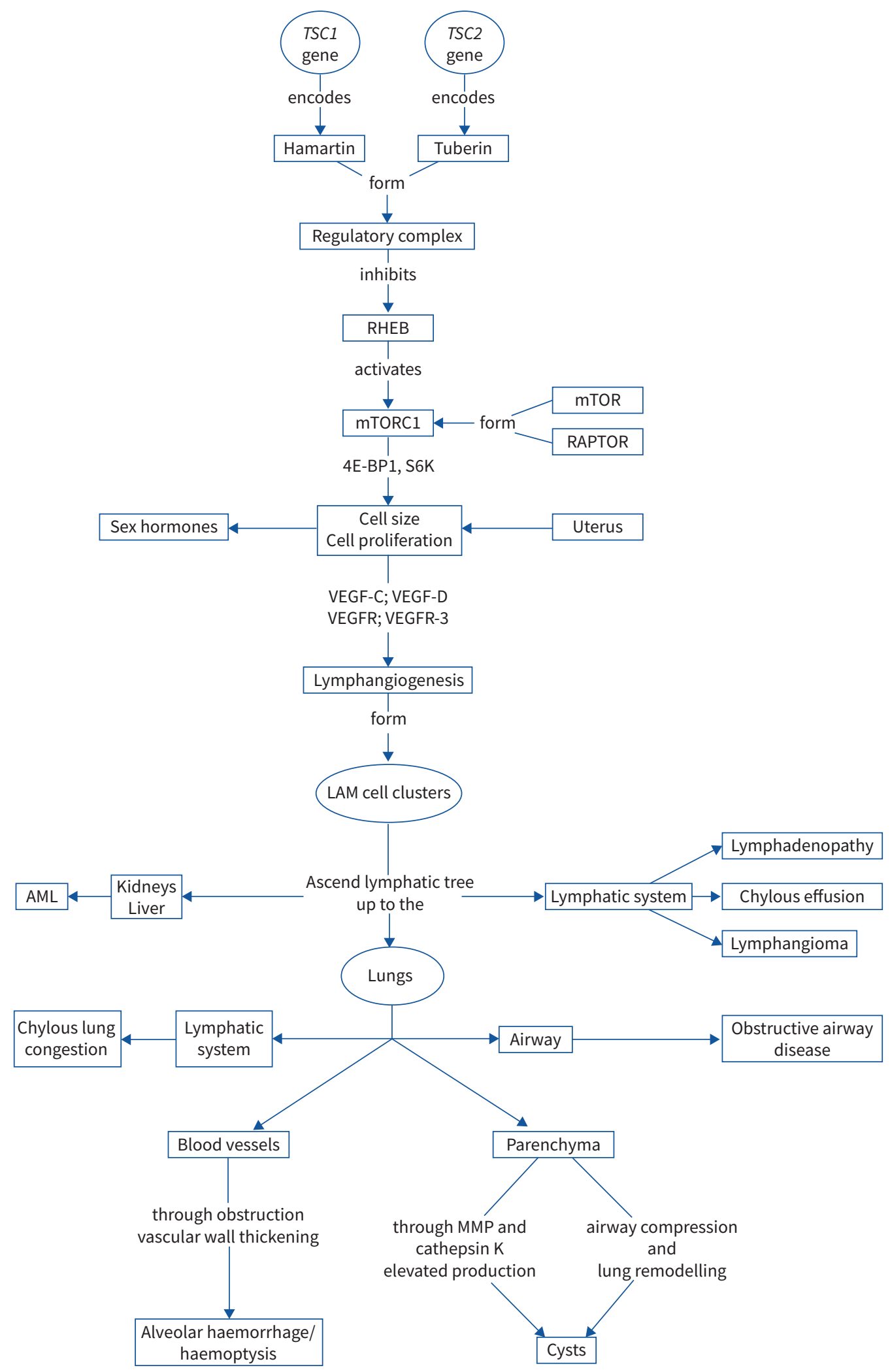

FIGURE 1 From tuberous sclerosis complex (TSC) to lymphangioleiomyomatosis (LAM), proposed schema of pathophysiology. RHEB: Ras homologue enriched in brain; mTOR: mammalian target of rapamycin; mTORC1: mTOR complex-1; RAPTOR: regulatory-associated protein of mTOR; VEGF: vascular endothelial growth factor; VEGFR: vascular endothelial growth factor receptor; AML: angiomyolipoma; MMP: matrix metalloproteinase. 

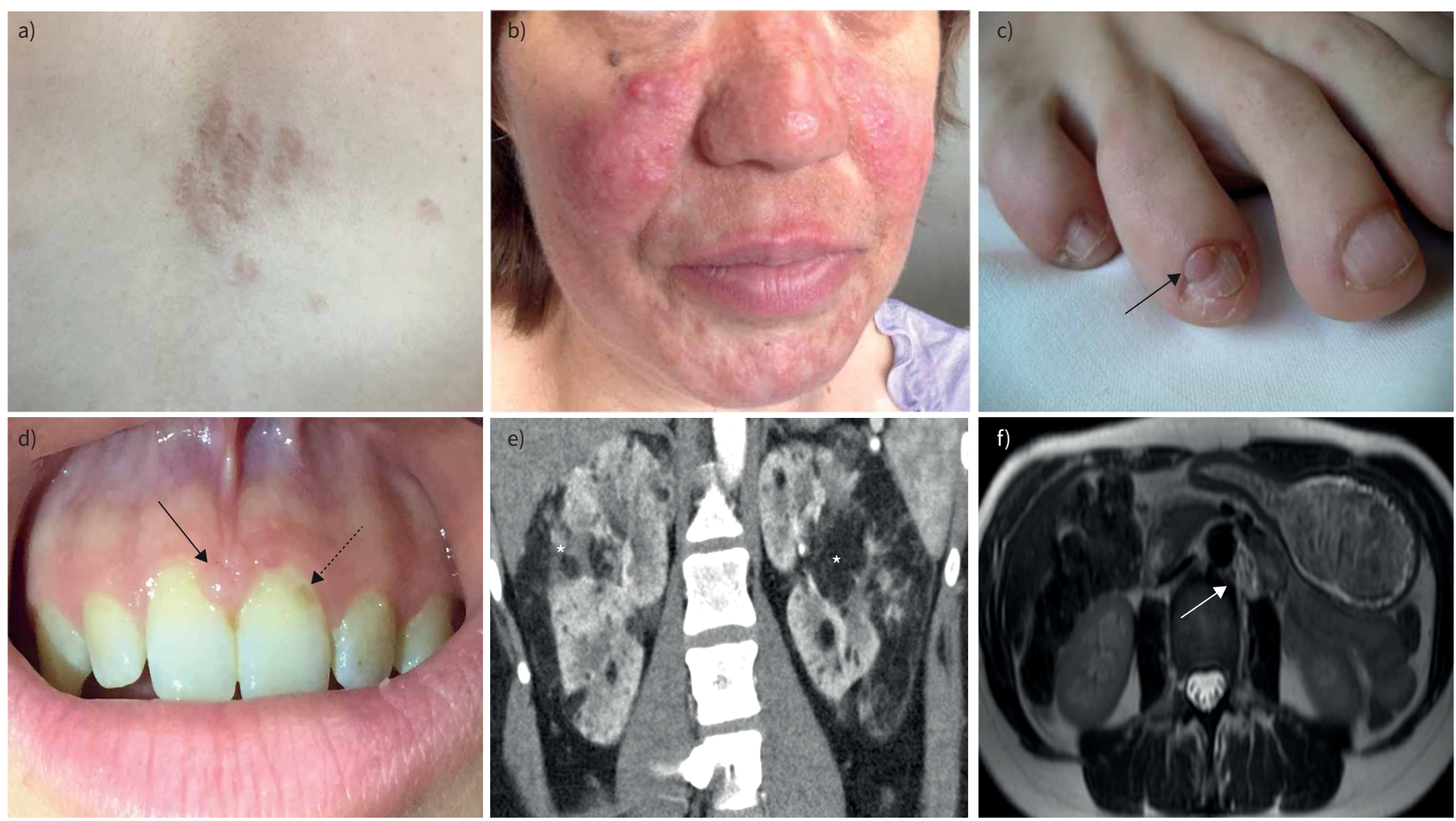

FIGURE 2 Extrathoracic manifestations of tuberous sclerosis complex. a) Shagreen patch; b) angiofibromas; c) ungual fibroma (arrow); d) oral fibroma (arrow) and dental enamel pits (dotted arrow); e) bilateral renal angiomyolipoma (asterisks); f) retroperitoneal lymphangioma (arrow).

manifestations have an age-related expression, thus warranting periodic and thorough follow-up. Some features appear in childhood and do not progress into adulthood (for example, cardiac rhabdomyoma), some may develop only in adults (such as LAM), while others are present throughout the individual's lifespan (namely facial angiofibroma). TSC2 mutation tends to cause a more severe clinical disease than other mutations, especially with regards to neurological, renal and pulmonary features. Furthermore, no TSC manifestation is pathognomonic; a combination of certain features makes the diagnosis more reliable. Diagnostic criteria for TSC were first proposed in 1998 at the first International Tuberous Sclerosis Consensus Conference, and were updated in 2012 [1].

\section{Orocutaneous manifestations}

Dermatological and oral lesions account for four of the 11 major criteria and three of the six minor criteria. Knowledge and recognition of skin features is therefore necessary for the diagnostic process. These include hypomelanotic macules (or hypopigmented macules, ash-leaf spots), present in $90 \%$ of TSC patients, which represent the earliest visible sign of TSC at birth. Angiofibromas, present in $\sim 75 \%$ of patients, are hamartomatous nodules involving vascular and connective tissues, especially in the central areas of the face. Ungual fibromas (or Koenen tumours) are hamartomatous fibromas that affect up to $80 \%$ of patients, more commonly observed on the feet. Shagreen patches are more specific for TSC, present in $\sim 50 \%$ of patients, and are described as connective tissue hamartomas most common in the lower back [72]. As for oral lesions, dental enamel pits may be encountered in virtually all TSC patients, and oral fibromas in approximately half of them [39].

\section{Renal manifestations}

The more frequent renal manifestation of TSC is rAMLs, although they can also be found in the liver, in the uterus and, exceptionally, in the lungs [73-75]. The prevalence of rAMLs increases with age, being present in $9 \%$ of patients aged $<2$ years and in $79 \%$ of those aged $>40$ years. The TOSCA registry revealed that rAMLs were found in $52 \%$ of patients, with a higher frequency in females (58\% versus $42 \%$ in males) and in carriers of TSC2 mutations (59\% versus 33\% in TSC1). Symptoms include pain, bleeding, hypertension and impaired renal function, although most patients are asymptomatic [17]. Medical or invasive management prior to any complication intends to prevent life-threatening haemorrhages and avoid 
nephrectomy and renal insufficiency. Renal AMLs are also found in patients with S-LAM ( 50\%), but are usually unilateral and smaller. It is therefore recommended to suspect and evaluate for TSC if a LAM patient presents with bilateral rAMLs [26]. Furthermore, 30-35\% of patients with TSC develop multiple renal cysts, and as many as $5 \%$ of them meet the criteria for polycystic kidney disease [17, 39, 73]. In addition, $2 \%$ of TSC patients present with an overlap between autosomal dominant polycystic kidney disease and TSC, due to a contiguous gene deletion of TSC2-PKD1, the two genes lying adjacent to one another on chromosome 16p13.3 [76]. Renal cell carcinoma (RCC) is seen in 2-4\% of TSC patients, in contrast to $1 \%$ of the general population. It is seen more often with TSC2 mutation, and occurs in younger patients (age 30-40 years versus 55-60 years), with a female predominance. TSC-associated RCC is often multiple and bilateral, with histological heterogeneity within the same patient. Various histological types have been described: papillary, clear cell, chromophobe and oncocytoma more frequently seen. Compared to rAMLs, RCC grows faster and has no lipid content. Immunohistochemically, AML is HMB-45 positive and RCC is rather cytokeratin positive [77, 78].

\section{Neurological and neuropsychiatric manifestations}

The neurological and neuropsychiatric features of TSC generate the greatest burden of the disease. The majority of affected individuals have structural brain lesions that include cortical tubers, subependymal nodules, SEGA, radial migration lines and retinal astrocytic hamartomas, among others. Cortical tubers (from which derives the name of the disease) are present in $\sim 90 \%$ of the patients with a predilection for the frontal lobes. SEGA develops in up to $25 \%$ of patients [15], usually in the first two decades of life [39]. It is considered a slow-growing lesion; grade I according to the WHO classification. Epilepsy is present in 70-90\% of affected individuals [16, 79], and usually appears within the first year of life. TSC-associated neuropsychiatric disorders include intellectual disability, developmental delay, autism spectrum disorders and mood disorders [80]. Although globally underrecognised, up to two-thirds of patients suffer from mental health issues, 50\% have intellectual impairment and 40\% suffer from autism [39]. Of note, cognitive impairment may impact the diagnostic process and overall management.

\section{Thoracic manifestations}

LAM is the most common pulmonary manifestation in adult patients with TSC, especially females. Other thoracic features include MMPH, pneumothoraces and a variety of lymphatic manifestations (figure 3). TSC-LAM is more often asymptomatic than S-LAM (it is virtually asymptomatic in males [39]) and more frequently diagnosed through active screening. When symptomatic, the most common feature is dyspnoea.

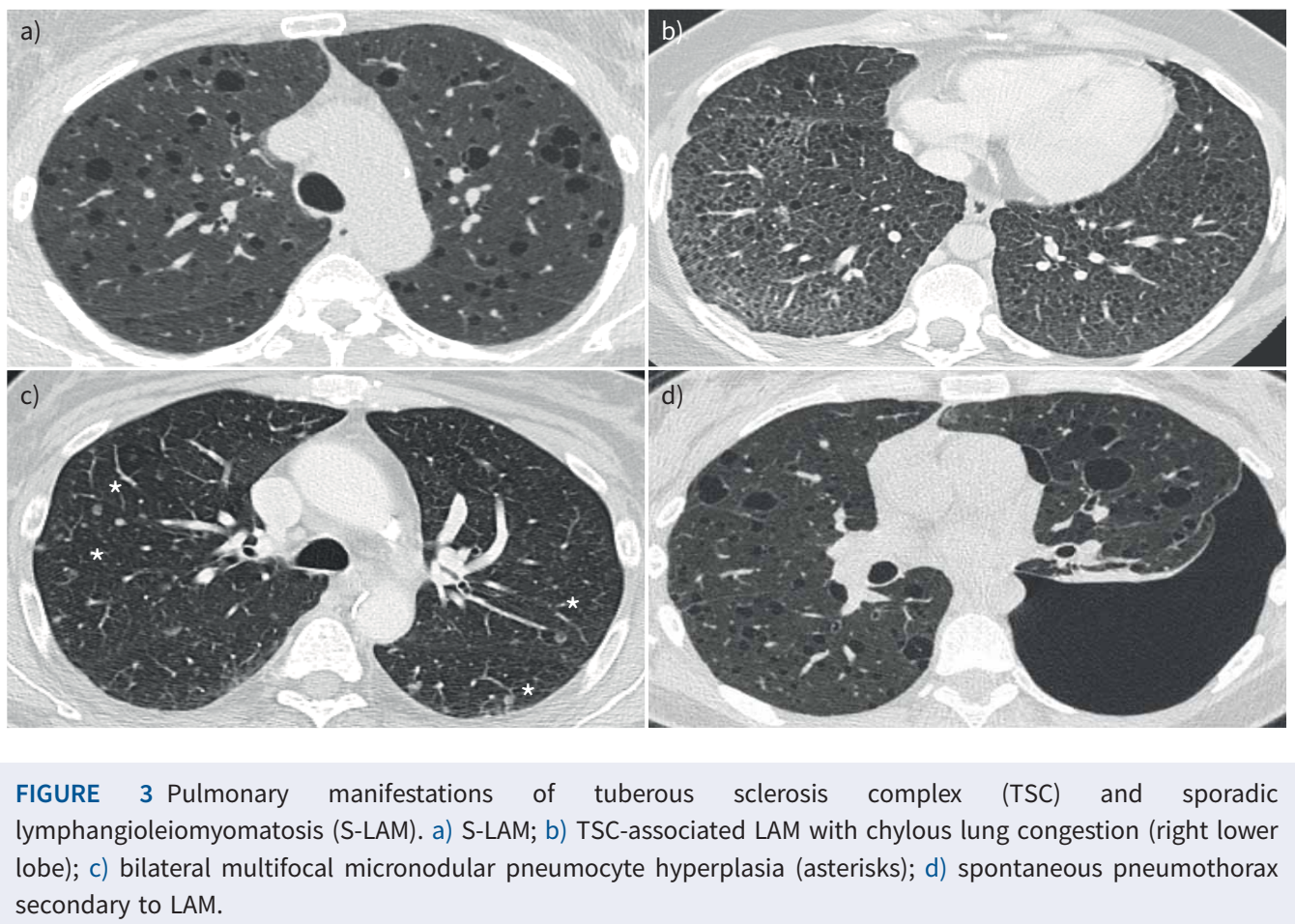


Spontaneous pneumothorax occurs in $45-60 \%$ of cases $[14,81]$. Chest pain, fatigue, cough and chyloptysis (expectoration of chylous material) are less frequently seen (table 1) [28, 81].

MMPH is a rare pulmonary manifestation of TSC and refers to nodular proliferation of type II pneumocytes along the alveolar septa. It is a histologically distinct entity from LAM, staining negative for HMB45 and positive for phospho-S6. However, MMPH lesions also show LOH for TSC genes and activation of mTOR pathway, implying a pathophysiology similar to LAM [82]. MMPH was first described in 1991 in a 38-year-old female with TSC [83]. Its exact prevalence is unknown, although it has been estimated to range between $40 \%$ and $60 \%$ [84]. Similar to TSC, MMPH has no sex predominance [85]. On high-resolution computed tomography (HRCT), MMPH appears as multiple solid, semi-solid or ground-glass nodules, which range in size from 1 to $10 \mathrm{~mm}$ and are usually upper-lobe predominant and peripheral [86]. MMPH is thought to be indolent and nonprogressive [87], although data are scarce. It needs to be differentiated from pre-malignant pulmonary lesions that may be found in association with LAM, such as atypical adenomatoid hyperplasia, especially when found in S-LAM [88]. Interestingly, a young male with TSC had MMPH lesions that disappeared upon treatment with an mTOR inhibitor, which was introduced for rAMLs [89].

Spontaneous pneumothorax affects between 55\% and 73\% of patients with LAM during their lifetime with an estimated relapse rate in the absence of surgery of $70 \%[8,28,31,84,90]$. Pneumothorax is the presenting symptom in $40 \%$ of cases [26]; inaugural pneumothorax is associated with a younger age at diagnosis and a better outcome, possibly due to early diagnosis [91, 92]. Patients with LAM have 1000 times greater risk for pneumothorax than the general population; the annual incidence is $8 \%$ after the first symptoms and 5\% after LAM diagnosis [11]. LAM-associated pneumothorax should be treated surgically, given that conservative management is associated with a higher rate of recurrence [90]. The latest American Thoracic Society (ATS)/Japanese Respiratory Society (JRS) guidelines suggest that patients with LAM be offered ipsilateral pleurodesis after their first pneumothorax rather than waiting for a first recurrence [93]. Pleurodesis reduces the risk of relapse by $\sim 50 \%$, but this risk remains much higher than after pleurodesis for primary spontaneous pneumothorax [11]. There is no difference between chemical or surgical pleurodesis; however, the pleural adhesions induced by the surgical techniques make the pleura difficult to dissect and more prone to intraoperative bleeding in a later procedure, such as lung transplantation. Total pleural coverage has been suggested as an alternative [94]. Of note, none of these

TABLE 1 Relevant features in tuberous sclerosis complex (TSC)-associated lymphangioleiomyomatosis (LAM) compared to sporadic lymphangioleiomyomatosis (S-LAM)

\begin{tabular}{|c|c|c|}
\hline Genetics & $\begin{array}{l}\text { Both TSC1 and TSC2 germinal mutations } \\
\text { TSC2 mutations more prevalent }\end{array}$ & $\begin{array}{c}\text { Somatic TSC2 mutations in affected organs: lung with } \\
\text { LAM, renal AML (TSC1 mutations extremely rare) }\end{array}$ \\
\hline Epidemiology & $\begin{array}{l}\text { Younger age at diagnosis } \\
\text { Reported in males (virtually asymptomatic) }\end{array}$ & $\begin{array}{l}\text { Young to middle-aged females } \\
\text { Exclusively in females }\end{array}$ \\
\hline Clinical presentation & $\begin{array}{l}\text { Less symptomatic } \\
\text { Spontaneous pneumothorax more frequent } \\
\text { Systematic screening in TSC patients }\end{array}$ & $\begin{array}{l}\text { Shortness of breath } \\
\text { Spontaneous pneumothorax } \\
\text { Incidental cysts on imaging }\end{array}$ \\
\hline Imaging & $\begin{array}{c}\text { Milder cystic lung disease } \\
\text { Coexistence of MMPH } \\
\text { Hepatic and renal AMLs (especially bilateral) more common } \\
\text { Extrathoracic TSC features }\end{array}$ & $\begin{array}{l}\text { Greater extent of lung cysts } \\
\text { Normal underlying pulmonary parenchyma } \\
\text { Lymphangioleiomyomas and chylothorax more frequent }\end{array}$ \\
\hline Lung physiology & $\begin{array}{l}\text { Normal lung function more frequent } \\
\text { Airflow obstruction and diffusion abnormalities possible }\end{array}$ & $\begin{array}{c}\text { Airflow obstruction and diffusion abnormalities more } \\
\text { frequent } \\
\text { Normal lung function possible }\end{array}$ \\
\hline Serum VEGF-D & $\begin{array}{c}\text { Elevated }\left(>800 \mathrm{pg} \cdot \mathrm{mL}^{-1}\right) \text { in }>95 \% \text { of patients } \\
\text { Higher serum concentrations }\end{array}$ & Elevated $\left(>800 \mathrm{pg} \cdot \mathrm{mL}^{-1}\right)$ in $60-70 \%$ of patients \\
\hline $\begin{array}{l}\text { Indications for mTOR } \\
\text { inhibitors }\end{array}$ & $\begin{array}{l}\text { For pulmonary LAM: same indications as in S-LAM } \\
\text { May be indicated for extrathoracic manifestations of TSC }\end{array}$ & $\begin{array}{c}\text { For patients with LAM with abnormal/declining lung } \\
\text { function } \\
\text { For selected patients with LAM with problematic chylous } \\
\text { effusions }\end{array}$ \\
\hline Prognosis & Generally milder disease & Lung transplantation more frequent \\
\hline
\end{tabular}


procedures should be considered a contraindication for lung transplantation [93, 95]. Furthermore, sirolimus has been shown to be promising in the prevention of recurrent pneumothorax in patients with LAM [96].

Lymphatic manifestations include chylothorax, chylous lung congestion, mediastinal lymphadenopathy and mediastinal and/or retroperitoneal lymphangioleiomyomas [84]. Chyle fluid collections are found in 30\% and in the peritoneal space in $10 \%$ of LAM patients. Direct invasion or obstruction of the thoracic duct by LAM cell clusters induces a reflux of chylous fluid into the lymphatic vessels of the mediastinum and lungs, causing chylothorax and parenchymal chylous congestion [25]. The latter presents as interstitial infiltrates, interlobular septal thickening and ground glass opacities, with or without consolidations [97]. Other aetiologies must be taken into account in the differential diagnosis, such as drug-induced pneumonitis and infections, especially Pneumocystis pneumonia, in patients treated with mTOR inhibitors. TSC patients are at higher risk of recurrent aspiration, especially those with important cognitive impairment or treated with antiepileptic drugs [84].

\section{Diagnosis}

\section{Diagnosis of TSC}

A diagnosis of TSC is established with a high level of confidence (definite TSC) if a pathogenic variant in one of the TSC genes, two major clinical features, or one major and two or more minor clinical features are present. A possible diagnosis of TSC is made if either only one major feature or only two minor features are encountered (tables 2 and 3) [1]. Routine genetic testing is generally not needed to confirm or rule out TSC, but may be useful in individuals who do not fulfil the criteria and for counselling purposes.

TABLE 2 Diagnostic criteria for tuberous sclerosis complex (TSC)

Genetic diagnostic criteria Clinical diagnostic criteria Major features

Minor features

\begin{tabular}{l} 
Diagnosis \\
Definite \\
\hline Possible
\end{tabular}

Possible
Either TSC1 or TSC2 pathogenic ${ }^{\#}$ mutation in DNA from normal tissue

Hypomelanotic macules ( $\geqslant 3, \geqslant 5 \mathrm{~mm}$ diameter)

Angiofibromas $(\geqslant 3)$ or fibrous cephalic plaque

Ungual fibromas $(\geqslant 2)$

Shagreen patch

Multiple retinal hamartomas

Cortical dysplasias (includes tubers and cerebral white matter radial migration lines)

Subependymal nodules

Subependymal giant cell astrocytoma

Cardiac rhabdomyoma

$$
\text { LAM }^{\natural,+}
$$

Angiomyolipomas $(\geqslant 2)^{+}$

"Confetti" skin lesions

Dental enamel pits $(>3)$

Intraoral fibromas $(\geqslant 2)$

Retinal achromic patch

Multiple renal cysts

Nonrenal hamartomas

\section{Genetic criteria}

OR

Two major features

OR

One major feature with $\geqslant 2$ minor features

Either one major feature

OR

$\geqslant 2$ minor features

LAM: lymphangioleiomyomatosis. \#: defined as a mutation that clearly inactivates the function of the TSC1 or TSC2 proteins (e.g. out-of-frame insertion/deletion or nonsense mutation), prevents protein synthesis (e.g. large genomic deletion) or is a missense mutation whose effect on protein function has been established by functional assessment. Other TSC1 or TSC2 variants whose effect on function is less certain do not meet these criteria, and are not sufficient to make a definite diagnosis of TSC; ": see table $3 ;^{+}$: a combination of LAM and angiomyolipomas without other features does not meet criteria for a definite diagnosis. Information from [1]. 


\section{Diagnosis of LAM}

The presence of TSC paves the way to a clinical diagnosis of LAM in presence of a characteristic HRCT, which is defined as the "presence of multiple, bilateral, round, well-defined, relatively uniform, thin-walled cysts in a diffuse distribution" [26, 93]. The intervening lung parenchyma is usually normal; however, in TSC patients, ill-defined ground-glass opacities corresponding to MMPH or septal thickening with or without ground-glass opacities consistent with chylous congestion may be present (table 3). The latest ATS/JRS guidelines recommend that clinical diagnosis of LAM should be established using the least invasive approach $[93,98]$. Diagnosis of S-LAM may be more challenging than TSC-LAM and requires the presence of one of the associated features besides characteristic HRCT, such as rAMLs, serum VEGF-D of $>800 \mathrm{pg} \cdot \mathrm{mL}^{-1}$, chylous effusion, lymphangiomyomas, demonstration of LAM cells in pleural fluid or lymph node aspiration/biopsy or histopathological confirmation after a lung biopsy or retroperitoneal/pelvic mass biopsy (figure 4). A thorough clinical history and physical examination has a pivotal role to rule out other alternative diagnosis for cystic lung disease, such as metastatic carcinoma, emphysema, light-chain deposition disease, Sjögren syndrome, pulmonary Langerhans cell histiocytosis and Birt-Hogg-Dubé syndrome [99-101].

\section{Pulmonary function tests}

Pulmonary function tests (PFTs) are an important tool for diagnosis, follow-up and management of patients with LAM. In a retrospective series from a LAM registry, airway obstruction was the most common physiological pattern (57.3\%), while normal and restrictive patterns were present in 33.9\% and $11.4 \%$, respectively. Low diffusing capacity of the lung for carbon monoxide $\left(D_{\text {LCO }}\right)$ was found in $56.9 \%$ of patients, and $17 \%$ of patients showed a positive bronchodilator response [28]. In a series of 143 patients, airway obstruction was similarly predominant (68\%) and $16 \%$ had a mixed physiology. Reversible airway obstruction was present in a quarter of patients. Interestingly, positive bronchodilator response was associated with a more severe airway obstruction, an accelerated rate of forced expiratory volume in $1 \mathrm{~s}\left(\mathrm{FEV}_{1}\right)$ decline and a solid rather than cystic pattern of LAM lesions at histology. However, $D_{\mathrm{LCO}}$ correlated better than $\mathrm{FEV}_{1}$ with LAM histologic score, a predictor of poor outcome. A positive bronchodilator response and a low $D_{\text {LCO }}$ may predict a rapid decline of lung function and a worse outcome [102, 103]. A positive bronchodilator response was not associated with a reduction of dynamic hyperinflation or improvement of exercise capacity following bronchodilator treatment [104]. Thereby, the role of bronchodilator therapy in such patients remains unclear.

$\mathrm{FEV}_{1}$ declines at a rate of $\sim 70-140 \mathrm{~mL} \cdot \mathrm{year}^{-1}$, with a tendency to a slower rate after menopause [12, 59]. Although their disease may be milder at diagnosis, patients with TSC-LAM have a similar rate of annual lung function decline [32]. A recent study compared incidental cases of S- versus TSC-LAM and found a similar pulmonary disease extent on HRCT and severity on PFTs. After adjusting for selection bias, Di MARCo et al. [29] concluded that patients with TSC- and S-LAM have indistinguishable natural history.

Implications of diagnosis, screening and surveillance

Patients with TSC have a significantly shorter survival than the general population [38]; their estimated life expectancy is reduced to 70 years [105]. Leading causes of death include renal disease, sudden unexpected death in epilepsy and LAM [38, 106, 107]. TSC-LAM patients have a shorter life expectancy (63 years) when compared to TSC patients without LAM [23, 105]. A Canadian study reported a higher mortality

TABLE 3 Diagnostic criteria for lymphangioleiomyomatosis (LAM)

Compatible clinical history

AND

Characteristic HRCT of the chest AND

One or more of:

Presence of TSC

Renal angiomyolipoma(s)

Elevated serum VEGF-D $>800 \mathrm{pg} \cdot \mathrm{mL}^{-1}$

Chylous effusion (pleural or ascites) confirmed by tap and biochemical analysis of the fluid

Lymphangioleiomyomas (lymphangiomyomas)

Demonstration of LAM cells or LAM cell clusters on cytological examination of effusions or lymph nodes

Histopathological confirmation of LAM by lung biopsy or biopsy of retroperitoneal or pelvic masses

HRCT: high-resolution computed tomography; TSC: tuberous sclerosis complex; VEGF: vascular endothelia growth factor. Reproduced and modified from [93] with permission. 


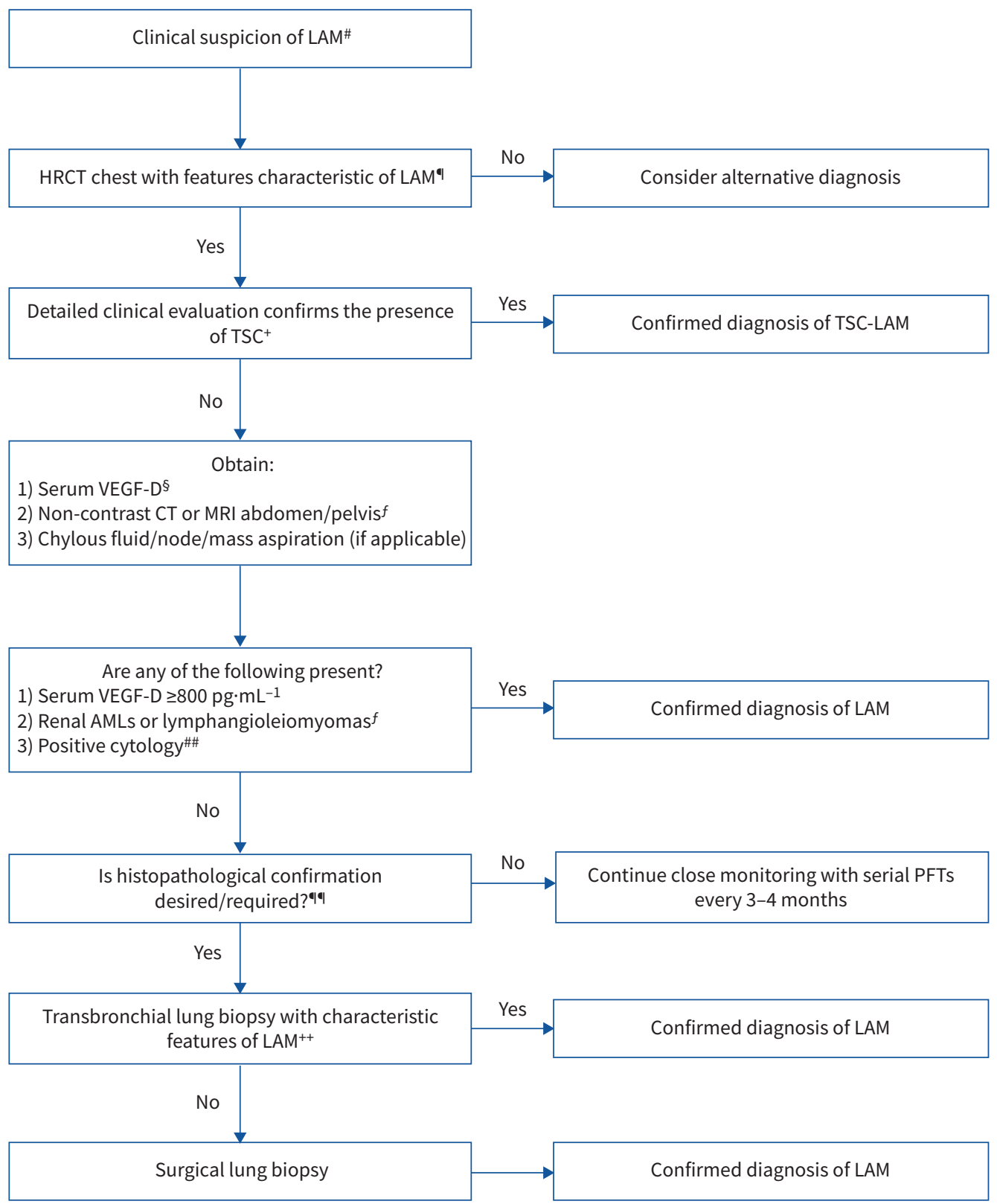

FIGURE 4 Proposed algorithm for the diagnosis of lymphangioleiomyomatosis (LAM) in a patient with compatible clinical history. HRCT: high-resolution computed tomography; TSC: tuberous sclerosis complex; VEGF: vascular endothelial growth factor; $\mathrm{CT}$ : computed tomography; MRI: magnetic resonance imaging; AML: angiomyolipoma; PFT: pulmonary function test. \#: suspect LAM clinically in young to middle-aged female patients presenting with worsening dyspnoea and/or pneumothorax/chylothorax. Most patients with LAM will have an obstructive defect on PFTs. Some patients, especially early in their disease course, may be asymptomatic and have normal PFTs. ": characteristic HRCT features of LAM include the presence of multiple, bilateral, round, well-defined, relatively uniform, thin-walled cysts in a diffuse distribution. The intervening lung parenchyma often appears normal on HRCT. Other associated features that can be seen on HRCT in some patients with LAM include the presence of chylous pleural effusion, pneumothorax, ground-glass opacity suggestive of chylous congestion or multiple tiny nodules characteristic of multifocal micronodular pneumocyte hyperplasia (in patients with TSC-LAM). ${ }^{+}$: referral to a TSC centre should be considered if there is uncertainty regarding the diagnosis of TSC. Features suggestive of TSC include the presence of any of the following: subungual fibromas, facial angiofibromas, hypomelanotic macules, confetti lesions, Shagreen patches, positive family history of TSC, history of seizures or cognitive impairment, or presence of cortical dysplasias, subependymal nodules and/or subependymal giant cell astrocytomas on brain imaging. Routine brain imaging is not indicated if clinical suspicion for TSC is low. Detailed diagnostic criteria for TSC to 
establish a definitive diagnosis have been published. ${ }^{\S}$ : serum VEGF-D is currently available in the USA as a College of American Pathologists/Clinical Laboratory Improvement Amendments-certified test only through the translational trials laboratory at Cincinnati Children's Hospital Medical Center. Detailed instructions for proper collection, handling and shipping of VEGF-D specimens are available at the laboratory website: www. cincinnatichildrens.org/ttdsl/. ${ }^{f}$ : the diagnosis of AML can usually be made radiographically on the basis of the presence of fat in the tumours. Routine use of contrast is not required or recommended for the diagnosis of AMLs. Contrast is useful to define the aneurysmal burden and other vascular characteristics of the tumour, such as for evaluation of the potential for haemorrhage or planning for embolisation. Similarly, lymphangioleiomyomas can typically be diagnosed on the basis of characteristic radiographic appearance. \#\#: the sensitivity of cytological analysis of pleural fluid for the diagnosis of LAM requires further investigation and may only be available at select centres. In a majority of patients with chylous effusions, the diagnosis of LAM can be established on the basis of elevated serum VEGF-D. "थ. the decision to obtain tissue confirmation via invasive means should be individualised. For some patients with mild disease and a paucity of symptoms, a probable clinical diagnosis of LAM with serial monitoring may be sufficient if a definitive diagnosis of LAM would not change management and some level of diagnostic uncertainty is acceptable to the patient and the clinician. Every attempt should be made to establish the diagnosis of LAM with certainty before initiation of pharmacological therapy with mechanistic target of rapamycin inhibitors. ${ }^{++}$: transbronchial lung biopsy has an estimated yield of $>50 \%$ for the diagnosis of LAM, and markers of parenchymal LAM burden such as abnormal diffusing capacity of the lung for carbon monoxide are associated with an increased diagnostic yield. Transbronchial lung biopsy appears to be safe in LAM on the basis of case reports and small series, but additional studies are required. Consultation with an expert centre is recommended in cases where transbronchial biopsy is being considered, and for interpretation of the biopsy. Reproduced and modified from [93] with permission.

rate in patients with LAM (including S- and TSC-LAM) than in those with TSC, TSC-LAM and a randomly selected control population; $28 \%$ of patients with TSC-LAM died compared to $15 \%$ in the control group over the 16-year study period, and the mean age of death was 18 years younger [108]. Therefore, the international TSC Consensus Group recommends to start screening at the age of 18 years with HRCT every 5-10 years in asymptomatic individuals and every 2-3 years once lung cysts are detected, along with annual PFTs and 6-min walk tests [109]. Likewise, the 2010 European Respiratory Society guidelines for the diagnosis and management of LAM recommend that females with TSC undertake a chest HRCT at the age of 18 years; if negative, they suggest repeating it only at the age of 30-40 years [26].

Reciprocally, screening for TSC in patients presenting with LAM impacts patient care and counselling. TSC is transmitted in an autosomal dominant manner, even when caused by de novo pathogenic mutations in TSC1 or TSC2 genes, as is the case for two-thirds of patients. The other third may have inherited the mutation from a parent with a mild phenotype and who remains undiagnosed [2]. Patients presenting with LAM should have a thorough personal and family history taken concerning the manifestations of TSC. Physical examination should include the skin, retina and nervous system by a physician familiar with the manifestations of TSC. In addition, patients with LAM and bilateral rAMLs, or in whom doubt remains should be referred to a clinical geneticist for full evaluation. Brain imaging may be useful in the workup of suspected TSC, or when meningioma is suspected [26, 93].

\section{Pulmonary hypertension}

Pulmonary hypertension is a known complication of LAM, albeit with limited published data regarding its prevalence and characteristics. The prevalence is estimated to be $7 \%$ [110-112]. Pre-capillary pulmonary hypertension is usually mild with a mean pulmonary artery pressure of $29-32 \mathrm{mmHg}$, and is identified after a mean 9 years after the diagnosis of LAM. Haemodynamic features correlate with PFTs, especially $\mathrm{FEV}_{1}$ and $D_{\mathrm{LCO}}[111,112]$. In light of these data, the 6th World Symposium on Pulmonary Hypertension proposed that pulmonary hypertension in LAM be classified under pulmonary hypertension due to lung diseases/hypoxia group (group 3) instead of group 5 (unclear and/or multifactorial mechanisms) [113]. A screening echocardiogram is recommended in patients with severe disease, in those with long-term oxygen therapy and in those considered for lung transplantation [26].

Particular considerations

\section{Pregnancy in patients with LAM}

LAM cells frequently express receptors for oestrogen and progesterone. Consequently, it was hypothesised that LAM is a hormone-dependent disease and females were recommended to avoid pregnancy for fear of disease progression or complications due to increased oestrogen load during pregnancy. Case reports 
suggest that LAM may be exacerbated by exogenous oestrogens [114]. CoHEN et al. [58] found that females who had never been pregnant or diagnosed with LAM after pregnancy had better FEV $\mathrm{F}_{1}$ and $D_{\mathrm{LCO}}$ than those who were diagnosed before and during their pregnancy. In a series of 50 patients with LAM, JoHNSON and TATTERSFIELD [30] reported pregnancy in 28 patients, of whom three were diagnosed before pregnancy and four during their pregnancy. Of these seven pregnancies, five were complicated by chylous effusion ( $n=2)$ and pneumothoraces $(n=3)$. The overall incidence of complications was 11 times higher during pregnancy. TAVEIRA-DaSilva et al. [10] retrospectively assessed lung function and CT scans before and after pregnancy in 16 females with LAM. Five patients suffered pneumothoraces during pregnancy, of which four were bilateral. There was an increased rate of loss of lung function, with mean \pm SD $\mathrm{FEV}_{1}$ deteriorating from $77 \pm 19 \%$ to $64 \pm 25 \%$ predicted and $D_{\text {LCO }}$ from $66 \pm 26 \%$ to $57 \pm 26 \%$ predicted. 10 patients had greater rates of decline after pregnancy compared to their pre-conception state. Cyst scores worsened in all cases where a CT scan was available. It was not possible to predict the impact of pregnancy according to pre-pregnancy lung function [10]. Despite the need to address this subject, data remain scarce and limited to case reports and retrospective observations. Preconception counselling and management should be based on a case-by-case discussion.

\section{Air travel}

Air travel is a known risk factor for pneumothorax in LAM patients. A lower atmospheric pressure increases the volume of pulmonary cysts, conceivably facilitating their rupture with consecutive pneumothorax. The risk of pneumothorax in LAM patients is 1000 times higher than in the general population, and about three times higher after air travel as compared to baseline [11]. The risk is significantly higher during the first 30 days following the flight [11]. Interestingly, air travel-related pneumothorax may not always be symptomatic [115]. Despite this, there is no specific recommendation with regards to air travel in patients with LAM and it is not systematically contraindicated. Patients should be educated about signs and symptoms of pneumothorax prior to flying and advised to seek medical advice if suggestive symptoms occur $[26,116]$. The safety of air travel following a pneumothorax in patients with LAM has not been studied. The British Thoracic Society recommends confirming the resolution on a chest radiograph and to wait a further 7 days before the next flight [116].

\section{Treatments}

\section{mTOR inhibitors}

Up until 2008, management of LAM was primarily supportive, referring to smoking cessation programmes, vaccination and avoidance of exogenous oestrogens, as well as education regarding air travel, pneumothorax and pregnancy [26]. The identification of TSC1 and TSC2 mutations in TSC, and somatic mutations in S-LAM led to a better understanding of the pathophysiology. The identification of the dysregulation in the hamartin-tuberin complex of mTORC1, which lies downstream of the signalling pathway related to proliferation and cell growth foreshadowed the therapeutic potential of mTOR inhibitors for diverse TSC manifestations. To date, sirolimus is the only mTOR inhibitor approved for patients with LAM by the United States Food and Drug Administration, European Medicines Agency and Pharmaceuticals and Medical Devices Agency of Japan. The latest ATS/JRS guidelines recommend sirolimus use in patients with LAM with abnormal and/or declining lung function and in selected cases of chylous effusions [98].

Sirolimus was first studied in a small population of patients displaying rAMLs, either with TSC or S-LAM [117]. In this nonrandomised, open-label trial, sirolimus reduced the size of rAMLs and increased $\mathrm{FEV}_{1}$ during the 12-month active treatment period. Other subsequent studies reported similar results in S-LAM patients [118-120]. The MILES trial was the first randomised, placebo-controlled, double-blind trial that demonstrated the efficacy of sirolimus in patients with LAM and moderate pulmonary impairment $\left(\mathrm{FEV}_{1}\right.$ $<70 \%$ ) [12]. During the 12-month treatment period, sirolimus stabilised lung function, with a between-group difference in the mean change of $\mathrm{FEV}_{1}$ of $153 \mathrm{~mL}$ (11\%). In addition, it improved quality of life and symptoms, and decreased serum VEGF-D levels. These benefits were lost when sirolimus was discontinued during the following 12-month observation period, during which lung function deteriorated at the same rate as in the placebo arm. These benefits were maintained at 4 years in a retrospective study in patients with S-LAM, with mild adverse events and persisting decreased levels of VEGF-D [121]. A population study of the MILES trial patients suggested that VEGF-C may be a promising biomarker to assess treatment response to sirolimus, although less promising for the diagnosis of LAM [122]. In addition, sirolimus has demonstrated additional benefits in other pulmonary manifestations, such as chylous effusion [123], chylous congestion [97] (resulting often in a complete resolution) and in abdominal lymphangiomas [124]. Whether sirolimus decreases the risk of pneumothorax is unknown, although an observational study of five females with LAM and recurrent pneumothorax treated with sirolimus for 5-36 months showed some promising results [96]. 
Aphthous ulcers or stomatitis were observed in the majority of patients and resolved with dose reduction or topical therapy. Diarrhoea and infectious complications, mainly pulmonary, were also common. Drug-induced pneumonitis, although not reported in the MILES trial, is a frequent side-effect in renal transplant patients and has also been described in LAM patients treated with sirolimus. It should be suspected, among other diagnoses, in patients presenting with worsening dyspnoea and ground-glass opacities on HRCT [125]. Approximately half of patients have an elevation of serum lipid levels due to sirolimus [117]. If there was an indication to treat the hyperlipidaemia, the use of simvastatin rather atorvastatin has been shown to be well tolerated and might have an added benefit of controlling the disease [126].

Everolimus, another mTOR inhibitor, was associated with an improvement of $\mathrm{FEV}_{1}$, an increase in 6-min walk distance, a stabilisation of forced vital capacity (FVC) and a reduction of VEGF-D serum level in patients with $\mathrm{FEV}_{1}$ 30-90\% predicted [127]. In addition, it showed benefits in patients with other manifestations of TSC, such as SEGAs (by decreasing tumour size by $>50 \%$ [128]), rAMLs, cutaneous features and resistant epilepsy [129, 130]. A recent meta-analysis supports the latter findings; mTOR inhibitors were associated with improved lung function and reduced size of rAMLs [131]. Compared to sirolimus, everolimus has a shorter half-life and better bioavailability, making it an interesting option for patients awaiting transplantation [132].

Longer studies are warranted to evaluate long-term effects of mTOR inhibitors. In the MILES trial, only patients with an $\mathrm{FEV}_{1}<70 \%$ of predicted were eligible [12]; whether patients with better lung function would also benefit from sirolimus is still unknown. Interestingly, in a prospective cohort of 47 patients with progressive lung impairment secondary to LAM, patients with a higher $\mathrm{FEV}_{1}$ at baseline and shorter disease duration had a significantly higher $\mathrm{FEV}_{1}$ improvement [133]. Finally, care must be taken when prescribing mTOR inhibitors in patients already receiving antiepileptic drugs, given the risk of drug-drug interactions.

\section{Investigational treatments}

Doxycycline, a tetracycline antibiotic, has been studied in the treatment of LAM because of its inhibitory effects on production and activity of MMPs that promote lung destruction in LAM. However, a 2-year randomised double-blind trial of 23 female patients failed to demonstrate a difference in the decline in $\mathrm{FEV}_{1}$ (the primary end-point), FVC, $D_{\mathrm{LCO}}$, shuttle walk distance or quality of life [132], despite a decrease in urine MMP levels [134]. The ATS/JRS guidelines advise against its use in LAM patients [98].

Hormone therapy has been investigated because of the putative role of sex hormones in disease pathogenesis. No randomised controlled trial has studied progesterone and observational studies are overall negative, although data are conflicting. A prospective study of 11 patients showed that triptorelin, a gonadotrophin-releasing hormone inducing gonadal suppression in pre-menopausal females, did not preclude the loss of lung function, while causing loss of bone mineral density [135]. The routine use of hormonal therapy is not recommended [26, 98].

\section{Lung transplantation}

Lung transplantation is recommended for patients with LAM who reach a New York Heart Association functional class III or IV with limited exercise capacity and severely reduced lung function [26]. LAM is a rare cause for lung transplantation (1\%). Recent observations showed an improved survival rate; up to $73.7 \%$ at 10 years [136] and a median survival of 12 years [137] following transplantation. TSC itself should not be considered a contraindication, although serious comorbidities are much more frequent than in patients with S-LAM [138], namely cognitive impairment.

Cases of LAM recurrence following lung transplantation have been reported [139, 140], consistent with LAM being a benign low-grade metastatic neoplasm. In clinical practice, with the advent of mTOR inhibitors, few patients may still require lung transplantation. Of note, sirolimus use before transplantation has been associated with impaired wound healing and bronchial dehiscence, eventually leading to death [141, 142]. Low-dose sirolimus may be continued in patients listed for lung transplantation, discontinued at the time of transplantation and resumed if necessary post-transplantation [143]. A recent cohort study of 13 patients suggested that, in selected patients, the introduction of sirolimus within the first month was safe [144]. However, more studies are needed to determine the optimal timing for resumption of sirolimus. The rationale to resume sirolimus after transplantation is to treat chylous effusion, to reduce LAM recurrence rate and to manage extrapulmonary manifestations [145]. 
Future perspectives

Although mTOR inhibitors are effective at stabilising lung function, the rate of lung function decline resumes once the drug is discontinued [12], since mTOR inhibitors are cytostatic rather than cytotoxic on LAM cells and do not cure the disease. Other therapeutic strategies are under study. LAM cells express several antigens found in melanoma, including gp100, MART-1, TRP-2 and TRP-1. The first three are effective targets for T-cells in melanoma, while the latter is a humoral target antigen [65]. These antigens evade immune detection through unknown mechanisms. It has been hypothesised that they may be targeted with melanoma immunotherapy via either immune checkpoint blockade or cytotoxic lymphocytes.

A marked reactivity for programmed death ligand-1 (PD-L1) in LAM nodules found in human lung as compared to control has been shown [146]. In a mouse model of LAM, a significantly increased number of T-cells in the lungs compared with controls, associated with an upregulation of PD-1-PD-L1 in LAM nodules has been evidenced. Furthermore, treatment with anti-PD-1 antibodies resulted in a longer survival in LAM mice, suggesting an interesting therapeutic avenue [147].

LAM cells are susceptible to cytotoxic, gp100 reactive and major histocompatibility complex (MHC) class I CD8 T-cells in vitro [65]. Based on this, HaN et al. [148] tested a proof-of-concept with adoptive transfer of specific T-cells in vivo as a possible treatment for LAM. They developed a murine model of pulmonary LAM and injected gp100-TCR-specific T-cells isolated from MHC complex-matched mice into their circulation. This procedure reduced, but did not eliminate, the tumour burden. The addition of anti-PD-1 antibody further decreased the number of LAM cells [148].

Other ways of improving immune responses to melanosomal antigens, and thus bypass T-cell exhaustion, have been studied in the context of melanoma, such as cancer vaccine immunotherapy, showing promise that may be translated to LAM [146].

\section{Conclusion}

TSC is a multifaceted genetic disorder with substantial heterogeneity. Pulmonary manifestations are common, especially LAM, which is one of the leading causes of morbidity and mortality in TSC. Pneumothorax is quite frequent and characterised with frequent recurrence even after surgery. mTOR inhibitors are the only approved treatment for patients with progressive or moderate-to-severe LAM, thus changing the therapeutic landscape in LAM and other TSC manifestations, notably rAMLs. Immunotherapy warrants evaluation in LAM, in the hope of extending the benefits of treatment beyond the clinical stabilisation already obtained with mTOR inhibitors.

Provenance: Commissioned article, peer reviewed.

Previous articles in the Series: No. 1: Daccord C, Good J-M, Morren M-A, et al. Brit-Hogg-Dubé syndrome. Eur Respir Rev 2020; 29: 200042. No. 2: Hadchouel A, Drummond D, Abou Taam R, et al. Alveolar proteinosis of genetic origins. Eur Respir Rev 2020; 29: 200187. No. 3: Cazzato S, Omenetti A, Ravaglia C, et al. Lung involvement in monogenetic interferonopathies. Eur Respir Rev 2021; 30: 200001. No. 4: Yokoyama T, Gochuico BR. HermanskyPudlak syndrome pulmonary fibrosis: a rare inherited interstitial lung disease. Eur Respir Rev 2021; 30: 200193. No. 5: van Moorsel CHM, Van der Vis JJ, Grutters JC. Genetic disorders of the surfactant system: focus on adult disease. Eur Respir Rev 2021; 30: 200085. No. 6: Bode SFN, Rohr J, Müller Quernheim J, et al. Pulmonary granulomatosis of genetic origin. Eur Respir Rev 2021; 30: 200152. No. 7: Borie R, Crestani B, Guyard A, et al. Interstitial lung disease in lysosomal storage disorders. Eur Respir Rev 2021; 30: 200363.

Conflict of interest: Y. Rebaine has nothing to disclose. M. Nasser has nothing to disclose. B. Girerd has nothing to disclose. C. Leroux has nothing to disclose. V. Cottin reports personal fees from Novartis, outside the submitted work.

\section{References}

1 Northrup H, Krueger DA, Roberds S, et al. Tuberous sclerosis complex diagnostic criteria update: recommendations of the 2012 International Tuberous Sclerosis Complex Consensus Conference. Pediatr Neurol 2013; 49: 243-254.

2 Peron A, Northrup H. Tuberous sclerosis complex. Am J Med Genet C Semin Med Genet 2018; 178: 274-277.

3 Auvin S, Bissler JJ, Cottin V, et al. A step-wise approach for establishing a multidisciplinary team for the management of tuberous sclerosis complex: a Delphi consensus report. Orphanet J Rare Dis 2019; 14: 91. 
4

The European Parliament and the Council of the European Union. Regulation (EC) No 141/2000 of the European Parliament and of the Council of 16 December 1999 on orphan medicinal products. Off J Eur Union 2000; L18: 1-5.

5 Aronson JK. Rare diseases and orphan drugs. Br J Clin Pharmacol 2006; 61: 243-245.

6 User's Guide. 3rd Edn. Rockville, Agency for Healthcare Research and Quality, 2014. Available from: https:// ncbi.nlm.nih.gov/books/NBK208609/ Characterized by Smooth Muscle Proliferation. Boca Raton, CRC Press, 1999; pp. 9-31.

8 Urban T, Lazor R, Lacronique J, et al. Pulmonary lymphangioleiomyomatosis: a study of 69 patients. Medicine 1999; 78: 321-337.

al. The NHLBI LAM Registry: prognostic physiologic and radiologic biomarkers emerge from a 15-year prospective longitudinal analysis. Chest 2019; 155: 288-296. Taveira-DaSilva AM, Johnson SR, Julien-Williams P, et al. Pregnancy in lymphangioleiomyomatosis: clinical and lung function outcomes in two national cohorts. Thorax 2020; 75: 904-907.

11 Gonano C, Pasquier J, Daccord C, et al. Air travel and incidence of pneumothorax in lymphangioleiomyomatosis. Orphanet J Rare Dis 2018; 13: 222.

12 McCormack FX, Inoue Y, Moss J, et al. Efficacy and safety of sirolimus in lymphangioleiomyomatosis. $N$ Engl J Med 2011; 364: 1595-1606.

13 Kingswood JC, Bruzzi P, Curatolo P, et al. TOSCA - first international registry to address knowledge gaps in the natural history and management of tuberous sclerosis complex. Orphanet J Rare Dis 2014; 9: 182. Kingswood JC, D'Augères GB, Belousova $\mathrm{E}$, et al. TuberOus SClerosis registry to increase disease Awareness (TOSCA) - baseline data on 2093 patients. Orphanet J Rare Dis 2017; 12: 2. Jansen AC, Belousova E, Benedik MP, et al. Clinical characteristics of subependymal giant cell astrocytoma in tuberous sclerosis complex. Front Neurol 2019; 10: 705.

16 Nabbout R, Belousova E, Benedik MP, et al. Epilepsy in tuberous sclerosis complex: findings from the TOSCA Study. Epilepsia Open 2019; 4: 73-84.

Kingswood JC, Belousova E, Benedik MP, et al. Renal angiomyolipoma in patients with tuberous sclerosis complex: findings from the TuberOus SClerosis registry to increase disease Awareness. Nephrol Dial Transplant 2019; 34: 502-508.

18 O'Callaghan FJK, Clarke AC, Joffe H, et al. Tuberous sclerosis complex and Wolff-Parkinson-White syndrome. Arch Dis Child 1998; 78: 159-162.

19 Devlin LA, Shepherd CH, Crawford H, et al. Tuberous sclerosis complex: clinical features, diagnosis, and prevalence within Northern Ireland. Dev Med Child Neurol 2006; 48: 495-499. Hallett L, Foster T, Liu Z, et al. Burden of disease and unmet needs in tuberous sclerosis complex with neurological manifestations: systematic review. Curr Med Res Opin 2011; 27: 1571-1583.

Hong C-H, Darling TN, Lee $\mathrm{C}-\mathrm{H}$. Prevalence of tuberous sclerosis complex in Taiwan: a national population-based study. Neuroepidemiology 2009; 33: 335-341. tuberous sclerosis complex. Mayo Clin Proc 2000; 75: 591-594.

Cudzilo CJ, Szczesniak RD, Brody AS, et al. Lymphangioleiomyomatosis screening in women with tuberous sclerosis. Chest 2013; 144: 578-585. (LAM) in patients with tuberous sclerosis complex. Am J Respir Crit Care Med 2001; 164: 669-671. Gupta R, Kitaichi M, Inoue Y, et al. Lymphatic manifestations of lymphangioleiomyomatosis. Lymphology 2014; 47: 106-117. management of lymphangioleiomyomatosis. Eur Respir J 2010; 35: 14-26. Kim W, Giannikou K, Dreier JR, et al. A genome-wide association study implicates NR2F2 in lymphangioleiomyomatosis pathogenesis. Eur Respir J 2019; 53: 1900329.

28 Ryu JH, Moss J, Beck GJ, et al. The NHLBI lymphangioleiomyomatosis registry: characteristics of 230 patients at enrollment. Am J Respir Crit Care Med 2006; 173: 105-111.

29 Di Marco F, Terraneo S, Dias OM, et al. Natural history of incidental sporadic and tuberous sclerosis complex associated lymphangioleiomyomatosis. Respir Med 2020; 168: 105993. Johnson SR, Tattersfield AE. Clinical experience of lymphangioleiomyomatosis in the UK. Thorax 2000; 55: 1052-1057.

31 Taylor JR, Ryu J, Colby TV, et al. Lymphangioleiomyomatosis. Clinical course in 32 patients. N Engl J Med 1990; 323: 1254-1260.

32 Taveira-DaSilva AM, Jones AM, Julien-Williams P, et al. Severity and outcome of cystic lung disease in women with tuberous sclerosis complex. Eur Respir J 2015; 45: 171-180. 
Muzykewicz DA, Sharma A, Muse V, et al. TSC1 and TSC2 mutations in patients with lymphangioleiomyomatosis and tuberous sclerosis complex. J Med Genet 2009; 46: 465-468.

Adriaensen MEAPM, Schaefer-Prokop CM, Duyndam DAC, et al. Radiological evidence of lymphangioleiomyomatosis in female and male patients with tuberous sclerosis complex. Clin Radiol 2011; 66: 625-628.

Ryu JH, Sykes AMG, Lee AS, et al. Cystic lung disease is not uncommon in men with tuberous sclerosis complex. Respir Med 2012; 106: 1586-1590.

Curatolo P, Bombardieri R, Jozwiak S. Tuberous sclerosis. Lancet 2008; 372: 657-668.

Crino PB. Evolving neurobiology of tuberous sclerosis complex. Acta Neuropathol 2013; 125: 317-332.

Zöllner JP, Franz DN, Hertzberg C, et al. A systematic review on the burden of illness in individuals with tuberous sclerosis complex (TSC). Orphanet J Rare Dis 2020; 15: 23.

Henske EP, Jóźwiak S, Kingswood JC, et al. Tuberous sclerosis complex. Nat Rev Dis Primers 2016; 2: 16035.

Dabora SL, Kwiatkowski DJ, Franz DN, et al. Mutational analysis in a cohort of 224 tuberous sclerosis patients indicates increased severity of TSC2, compared with TSC1, disease in multiple organs. Am J Hum Genet 2001; 68: 64-80.

Nellist M, Brouwer RWW, Kockx CEM, et al. Targeted next generation sequencing reveals previously unidentified TSC1 and TSC2 mutations. BMC Med Genet 2015; 16: 10.

Tyburczy ME, Dies KA, Glass J, et al. Mosaic and intronic mutations in TSC1/TSC2 explain the majority of TSC patients with no mutation identified by conventional testing. PLoS Genet 2015; 11: e1005637.

Henske EP, Neumann HPH, Scheithauer BW, et al. Loss of heterozygosity in the tuberous sclerosis (TSC2) region of chromosome band $16 \mathrm{p} 13$ occurs in sporadic as well as TSC-associated renal angiomyolipomas. Genes Chromosom Cancer 1995; 13: 295-298.

Sepp T, Yates JRW, Green AJ. Loss of heterozygosity in tuberous sclerosis hamartomas. J Med Genet 1996; 33: 962-964.

Au KS, Hebert AA, Roach ES, et al. Complete inactivation of the TSC2 gene leads to formation of hamartomas. Am J Hum Genet 1999; 65: 1790-1795.

Dibble CC, Elis W, Menon S, et al. TBC1D7 is a third subunit of the TSC1-TSC2 complex upstream of mTORC1. Mol Cell 2012; 47: 535-546.

Zech R, Kiontke S, Mueller U, et al. Structure of the tuberous sclerosis complex 2 (TSC2) N terminus provides insight into complex assembly and tuberous sclerosis pathogenesis. J Biol Chem 2016; 291 20008-20020.

Chebib N, Archer F, Bobet-Erny A, et al. Dysregulation of the endothelin pathway in lymphangioleiomyomatosis with no direct effect on cell proliferation and migration. Sci Rep 2018; 8: 14698.

Davis JM, Hyjek E, Husain AN, et al. Lymphatic endothelial differentiation in pulmonary lymphangioleiomyomatosis cells. J Histochem Cytochem 2013; 61: 580-590.

Dieterich LC, Ducoli L, Shin JW, et al. Distinct transcriptional responses of lymphatic endothelial cells to VEGFR-3 and VEGFR-2 stimulation. Sci Data 2017; 4: 170106.

Kumasaka T, Seyama K, Mitani K, et al. Lymphangiogenesis-mediated shedding of LAM cell clusters as a mechanism for dissemination in lymphangioleiomyomatosis. Am J Surg Pathol 2005; 29: 1356-1366. Henske EP, McCormack FX. Lymphangioleiomyomatosis - a wolf in sheep's clothing. J Clin Invest 2012; 122: 3807-3816.

Matsui K, Beasley MB, Nelson WK, et al. Prognostic significance of pulmonary lymphangioleiomyomatosis histologic score. Am J Surg Pathol 2001; 25: 479-484.

McCormack FX, Travis WD, Colby TV, et al. Lymphangioleiomyomatosis: calling it what it is: a low-grade, destructive, metastasizing neoplasm. Am J Respir Crit Care Med 2012; 186: 1210-1212.

Guo M, Yu J, Perl AK, et al. Single cell transcriptomic analysis identifies a unique pulmonary lymphangioleiomyomatosis cell. Am J Respir Crit Care Med 2020; 202: 1373-1387.

Badri KR, Gao L, Hyjek E, et al. Exonic mutations of TSC2/TSC1 are common but not seen in all sporadic pulmonary lymphangioleiomyomatosis. Am J Respir Crit Care Med 2013; 187: 663-665.

Prizant H, Taya M, Lerman I, et al. Estrogen maintains myometrial tumors in a lymphangioleiomyomatosis model. Endocr Relat Cancer 2016; 23: 265-280.

Cohen MM, Freyer AM, Johnson SR. Pregnancy experiences among women with lymphangioleiomyomatosis. Respir Med 2009; 103: 766-772.

Johnson SR, Tattersfield AE. Decline in lung function in lymphangioleiomyomatosis: relation to menopause and progesterone treatment. Am J Respir Crit Care Med 1999; 160: 628-633.

Gao L, Yue MM, Davis J, et al. In pulmonary lymphangioleiomyomatosis expression of progesterone receptor is frequently higher than that of estrogen receptor. Virchows Arch 2014; 464: 495-503.

Pacheco-Rodriguez G, Taveira-DaSilva AM, Moss J. Benign metastasizing leiomyoma. Clin Chest Med 2016; 37: 589-595.

Prizant $\mathrm{H}$, Sen A, Light A, et al. Uterine-specific loss of Tsc2 leads to myometrial tumors in both the uterus and lungs. Mol Endocrinol 2013; 27: 1403-1414. 
Travis WD, Brambilla E, Nicholson AG, et al. The 2015 World Health Organization Classification of Lung Tumors: impact of genetic, clinical and radiologic advances since the 2004 classification. J Thorac Oncol 2015; 10: 1243-1260.

Ferrans V, Yu Z-X, Nelson W, et al. Lymphangioleiomyomatosis (LAM): a review of clinical and morphological features. J Nippon Med Sch 2000; 67: 311-329.

Klarquist J, Barfuss A, Kandala S, et al. Melanoma-associated antigen expression in lymphangioleiomyomatosis renders tumor cells susceptible to cytotoxic T cells. Am J Pathol 2009; 175: 2463-2472.

Taveira-DaSilva AM, Steagall WK, Moss J. Lymphangioleiomyomatosis. Cancer Control 2006; 13: 276-285.

Hayashi T, Fleming M V, Stetler-Stevenson WG, et al. Immunohistochemical study of matrix metalloproteinases (MMPs) and their tissue inhibitors (TIMPS) in pulmonary lymphangioleiomyomatosis (LAM). Hum Pathol 1997; 28: 1071-1078.

Matsui K, Takeda K, Yu Z-X, et al. Role for activation of matrix metalloproteinases in the pathogenesis of pulmonary lymphangioleiomyomatosis. Arch Pathol Lab Med 2000; 124: 267-275.

Brentani MM, Carvalho CRR, Saldiva PH, et al. Steroid receptors in pulmonary lymphangiomyomatosis. Chest 1984; 85: 96-99.

Colley MH, Geppert E, Franklin WA. Immunohistochemical detection of steroid receptors in a case of pulmonary lymphangioleiomyomatosis. Am J Surg Pathol 1989; 13: 803-807.

Martignoni G, Pea M, Reghellin D, et al. PEComas: the past, the present and the future. Virchows Arch 2008; 452: 119-132.

Nguyen QD, DarConte MD, Hebert AA. The cutaneous manifestations of tuberous sclerosis complex. Am $J$ Med Genet C Semin Med Genet 2018; 178: 321-325.

Bissler JJ, Kingswood JC. Renal manifestation of tuberous sclerosis complex. Am J Med Genet C Semin Med Genet 2018; 178: 338-347.

Morita K, Shida Y, Shinozaki K, et al. Angiomyolipomas of the mediastinum and the lung. $J$ Thorac Imaging 2012; 27: 21-23.

Sun $\mathrm{X}$, Feng R, Zhang $\mathrm{Y}$, et al. Coexistence of pulmonary lymphangioleiomyomatosis and pulmonary angiomyolipoma. BMC Pulm Med 2016; 16: 120.

Brown SAW, Jacobi A, Mathur A, et al. Diffuse lung cysts in a man with polycystic kidney disease. Ann Am Thorac Soc 2017; 14: 795-798.

Lam HC, Siroky BJ, Henske EP. Renal disease in tuberous sclerosis complex: pathogenesis and therapy. Nat Rev Nephrol 2018; 14: 704-716.

Trnka P, Kennedy SE. Renal tumors in tuberous sclerosis complex. Pediatr Nephrol 2021; 36: 1427-1438.

Lu DS, Karas PJ, Krueger DA, et al. Central nervous system manifestations of tuberous sclerosis complex. Am J Med Genet C Semin Med Genet 2018; 178: 291-298.

De Vries PJ, Wilde L, De Vries MC, et al. A clinical update on tuberous sclerosis complex-associated neuropsychiatric disorders (TAND). Am J Med Genet C Semin Med Genet 2018; 178: 309-320.

Taveira-DaSilva AM, Moss J. Clinical features, epidemiology, and therapy of lymphangioleiomyomatosis. Clin Epidemiol 2015; 7: 249-257.

Hayashi T, Kumasaka T, Mitani K, et al. Loss of heterozygosity on tuberous sclerosis complex genes in multifocal micronodular pneumocyte hyperplasia. Mod Pathol 2010; 23: 1251-1260.

Popper HH, Juettner-Smolle FM, Pongratz MG. Micronodular hyperplasia of type II pneumocytes - a new lung lesion associated with tuberous sclerosis. Histopathology 1991; 18: 347-354.

Gupta N, Henske EP. Pulmonary manifestations in tuberous sclerosis complex. Am J Med Genet C Semin Med Genet 2018; 178: 326-337.

Muzykewicz DA, Black ME, Muse V, et al. Multifocal micronodular pneumocyte hyperplasia: computed tomographic appearance and follow-up in tuberous sclerosis complex. J Comput Assist Tomogr 2012; 36: 518-522.

Crivelli P, Ledda RE, Terraneo S, et al. Role of thoracic imaging in the management of lymphangioleiomyomatosis. Respir Med 2019; 157: 14-20.

Konno S, Shigemura M, Ogi T, et al. Clinical course of histologically proven multifocal micronodular pneumocyte hyperplasia in tuberous sclerosis complex: a case series and comparison with lymphangiomyomatosis. Respiration 2018; 95: 310-316.

Cho HH, Shim SS, Kim Y, et al. Sporadic lymphangioleiomyomatosis with multiple atypical adenomatoid hyperplasia: differentiation from multifocal micronodular pneumocyte hyperplasia. Clin Radiol 2010; 65: 765-767.

Lim KH, Silverstone EJ, Yates DH. Multifocal micronodular pneumocyte hyperplasia in tuberous sclerosis complex: resolution with everolimus treatment. Am J Respir Crit Care Med 2020; 201: e76.

Almoosa KF, Ryu JH, Mendez J, et al. Management of pneumothorax in lymphangioleiomyomatosis: effects on recurrence and lung transplantation complications. Chest 2006; 129: 1274-1281. 

nationwide cross-sectional study of presenting features and prognostic factors. Respirology 2007; 12: 523-530.

92 Oprescu N, McCormack FX, Byrnes S, et al. Clinical predictors of mortality and cause of death in lymphangioleiomyomatosis: a population-based registry. Lung 2013; 191: 35-42.

93 Gupta N, Finlay GA, Kotloff RM, et al. Lymphangioleiomyomatosis diagnosis and management: high-resolution chest computed tomography, transbronchial lung biopsy, and pleural disease management. An official American Thoracic Society/Japanese Respiratory Society clinical practice guideline. Am J Respir Crit Care Med 2017; 196: 1337-1348.

$94 \mathrm{Kim}$ DH, Ahn HY, Son BS, et al. Total pleural coverage followed by lung transplantation in patient with lymphangioleiomyomatosis. Gen Thorac Cardiovasc Surg 2019; 68: 1208-1211.

95 Weill D. Lung transplantation: indications and contraindications. J Thorac Dis 2018; 10: 4574-4587.

96 Zhou L, Ouyang R, Luo $\mathrm{H}$, et al. Efficacy of sirolimus for the prevention of recurrent pneumothorax in patients with lymphangioleiomyomatosis: a case series. Orphanet J Rare Dis 2018; 13: 168.

97 Moua T, Olson EJ, St Jean HC, et al. Resolution of chylous pulmonary congestion and respiratory failure in lymphangioleiomyomatosis with sirolimus therapy. Am J Respir Crit Care Med 2012; 186: 389-390.

98 McCormack FX, Gupta N, Finlay GR, et al. Official American Thoracic Society/Japanese Respiratory Society clinical practice guidelines: lymphangioleiomyomatosis diagnosis and management. Am J Respir Crit Care Med 2016; 194: 748-761.

99 Gupta N, Vassallo R, Wikenheiser-Brokamp KA, et al. Diffuse cystic lung disease. Part I. Am J Respir Crit Care Med 2015; 191: 1354-1366.

100 Gupta N, Vassallo R, Wikenheiser-Brokamp KA, et al. Diffuse cystic lung disease. Part II. Am J Respir Crit Care Med 2015; 192: 17-29.

101 Raoof S, Bondalapati P, Vydyula R, et al. Cystic lung diseases: algorithmic approach. Chest 2016; 150: 945-965.

102 Taveira-DaSilva AM, Hedin C, Stylianou MP, et al. Reversible airflow obstruction, proliferation of abnormal smooth muscle cells, and impairment of gas exchange as predictors of outcome in lymphangioleiomyomatosis. Am J Respir Crit Care Med 2001; 164: 1072-1076.

103 Taveira-DaSilva AM, Steagall WK, Rabel A, et al. Reversible airflow obstruction in lymphangioleiomyomatosis. Chest 2009; 136: 1596-1603.

104 Baldi BG, De Albuquerque ALP, Pimenta SP, et al. A pilot study assessing the effect of bronchodilator on dynamic hyperinflation in LAM. Respir Med 2013; 107: 1773-1780.

105 Zak S, Mokhallati N, Su W, et al. Lymphangioleiomyomatosis mortality in patients with tuberous sclerosis complex. Ann Am Thorac Soc 2019; 16: 509-512.

106 Shepherd CW, Gomez MR. Mortality in the Mayo Clinic Tuberous Sclerosis Complex Study. Ann NY Acad Sci 1991; 615: 375-377.

107 Amin S, Lux A, Calder N, et al. Causes of mortality in individuals with tuberous sclerosis complex. Dev Med Child Neurol 2017; 59: 612-617.

108 Kristof AS, Li PZ, Major P, et al. Lymphangioleiomyomatosis and tuberous sclerosis complex in Quebec: prevalence and health-care utilization. Chest 2015; 148: 444-449.

109 Krueger DA, Northrup H, International Tuberous Sclerosis Complex Consensus Group. Tuberous sclerosis complex surveillance and management: recommendations of the 2012 International Tuberous Sclerosis Complex Consensus Conference. Pediatr Neurol 2013; 49: 255-265.

110 Taveira-DaSilva AM, Hathaway OM, Sachdev V, et al. Pulmonary artery pressure in lymphangioleiomyomatosis: an echocardiographic study. Chest 2007; 132: 1573-1578.

111 Cottin V, Harari S, Humbert M, et al. Pulmonary hypertension in lymphangioleiomyomatosis: characteristics in 20 patients. Eur Respir J 2012; 40: 630-640.

112 Freitas CSG, Baldi BG, Jardim C, et al. Pulmonary hypertension in lymphangioleiomyomatosis: prevalence, severity and the role of carbon monoxide diffusion capacity as a screening method. Orphanet $J$ Rare Dis 2017; $12: 74$.

113 Simonneau G, Montani D, Celermajer DS, et al. Haemodynamic definitions and updated clinical classification of pulmonary hypertension. Eur Respir J 2019; 53: 1801913.

114 Shen A, Iseman MD, Waldron JA, et al. Exacerbation of pulmonary lymphangioleiomyomatosis by exogenous estrogens. Chest 1987; 91: 782-785.

115 Taveira-DaSilva AM, Burstein D, Hathaway OM, et al. Pneumothorax after air travel in lymphangioleiomyomatosis, idiopathic pulmonary fibrosis, and sarcoidosis. Chest 2009; 136: 665-670.

116 Ahmedzai S, Balfour-Lynn IM, Bewick T, et al. Managing passengers with stable respiratory disease planning air travel: British Thoracic Society recommendations. Thorax 2011; 66: Suppl. 1, i1-i30.

117 Bissler JJ, McCormack FX, Young LR, et al. Sirolimus for angiomyolipoma in tuberous sclerosis complex or lymphangioleiomyomatosis. N Engl J Med 2008; 358: 140-151. 
118 Davies DM, Johnson SR, Tattersfield AE, et al. Sirolimus therapy in tuberous sclerosis or sporadic lymphangioleiomyomatosis. N Engl J Med 2008; 358: 200-203.

119 Egan JJ, Remund KF, Corris P. Sirolimus for lymphangioleiomyomatosis lesions. N Engl J Med 2008; 358 : 1963-1964.

120 Sugimoto R, Nakao A, Yamane M, et al. Sirolimus amelioration of clinical symptoms of recurrent lymphangioleiomyomatosis after living-donor lobar lung transplantation. J Heart Lung Transplant 2008; 27: 921-924.

$121 \mathrm{Hu} \mathrm{S}, \mathrm{Wu} \mathrm{X}, \mathrm{Xu} \mathrm{W}$, et al. Long-term efficacy and safety of sirolimus therapy in patients with lymphangioleiomyomatosis. Orphanet J Rare Dis 2019; 14: 206.

122 Gupta N, Hagner M, Wu H, et al. Serum vascular endothelial growth factor-C as a marker of therapeutic response to sirolimus in lymphangioleiomyomatosis. Ann Am Thorac Soc 2020; 18: 174-177.

123 Taveira-DaSilva AM, Hathaway O, Stylianou M, et al. Changes in lung function and chylous effusions in patients with lymphangioleiomyomatosis treated with sirolimus. Ann Intern Med 2011; 154: 797-805.

124 Cottin V, Si-Mohamed S, Ahmad K, et al. mTOR inhibitors for the management of difficult lymphangioma in adults. Respir Med Res 2020; 77: 8-10.

125 Takada T, Mikami A, Kitamura N, et al. Efficacy and safety of long-term sirolimus therapy for Asian patients with lymphangioleiomyomatosis. Ann Am Thorac Soc 2016; 13: 1912-1922.

126 Krymskaya VP, Courtwright AM, Fleck V, et al. A phase II clinical trial of the Safety Of Simvastatin (SOS) in patients with pulmonary lymphangioleiomyomatosis and with tuberous sclerosis complex. Respir Med 2020; 163: 105898.

127 Goldberg HJ, Harari S, Cottin V, et al. Everolimus for the treatment of lymphangioleiomyomatosis: a phase II study. Eur Respir J 2015; 46: 783-794.

128 Franz DN, Belousova E, Sparagana S, et al. Long-term use of everolimus in patients with tuberous sclerosis complex: final results from the EXIST1 study. PLoS One 2016; 11: e0158476.

129 Bissler JJ, Kingswood JC, Radzikowska E, et al. Everolimus for angiomyolipoma associated with tuberous sclerosis complex or sporadic lymphangioleiomyomatosis (EXIST2): a multicentre, randomised, doubleblind, placebocontrolled trial. Lancet 2013; 381: 817-824.

130 French JA, Lawson JA, Yapici Z, et al. Adjunctive everolimus therapy for treatment-resistant focal-onset seizures associated with tuberous sclerosis (EXIST-3): a phase 3, randomised, double-blind, placebo-controlled study. Lancet 2016; 388: 2153-2163.

131 Gao N, Zhang $\mathrm{T}$, Ji J, et al. The efficacy and adverse events of mTOR inhibitors in lymphangioleiomyomatosis: systematic review and meta-analysis. Orphanet J Rare Dis 2018; 13: 134.

132 Wang Q, Luo M, Xiang B, et al. The efficacy and safety of pharmacological treatments for lymphangioleiomyomatosis. Respir Res 2020; 21: 55.

133 Bee J, Fuller S, Miller S, et al. Lung function response and side effects to rapamycin for lymphangioleiomyomatosis: a prospective national cohort study. Thorax 2018; 73: 369-375.

134 Chang WYC, Cane JL, Kumaran M, et al. A 2-year randomised placebo-controlled trial of doxycycline for lymphangioleiomyomatosis. Eur Respir J 2014; 43: 1114-1123.

135 Harari S, Cassandro R, Chiodini J, et al. Effect of a gonadotrophin-releasing hormone analogue on lung function in lymphangioleiomyomatosis. Chest 2008; 133: 448-454.

136 Ando K, Okada Y, Akiba M, et al. Lung transplantation for lymphangioleiomyomatosis in Japan. PLoS One 2016; 11: e0146749.

137 Khawar MU, Yazdani D, Zhu Z, et al. Clinical outcomes and survival following lung transplantation in patients with lymphangioleiomyomatosis. J Heart Lung Transplant 2019; 38: 949-955.

138 Maurer JR, Ryu J, Beck G, et al. Lung transplantation in the management of patients with lymphangioleiomyomatosis: baseline data from the NHLBI LAM registry. J Heart Lung Transplant 2007; 26: 1293-1299.

139 Benden C, Rea F, Behr J, et al. Lung Transplantation for Lymphangioleiomyomatosis: The European Experience. J Hear Lung Transplant 2009; 28: 1293-1299.

140 Zaki KS, Aryan Z, Mehta AC, et al. Recurrence of lymphangioleiomyomatosis: nine years after a bilateral lung transplantation. World J Transplant 2016; 6: 249-254.

141 King-Biggs MB, Dunitz JM, Park SJ, et al. Airway anastomotic dehiscence associated with use of sirolimus immediately after lung transplantation. Transplantation 2003; 75: 1437-1443.

142 Groetzner J, Kur F, Spelsberg F, et al. Airway anastomosis complications in de novo lung transplantation with sirolimus-based immunosuppression. J Heart Lung Transplant 2004; 23: 632-638.

143 El-Chemaly S, Goldberg HJ, Glanville AR. Should mammalian target of rapamycin inhibitors be stopped in women with lymphangioleiomyomatosis awaiting lung transplantation? Expert Rev Respir Med 2014; 8: 657-660.

144 Wojarski J, Żegleń S, Ochman M, et al. Early sirolimus-based immunosuppression is safe for lung transplantation patients: retrospective, single arm, exploratory study. Ann Transplant 2018; 23: 598-607. 
$145 \mathrm{Xu} \mathrm{KF}$, Tian X, Yang Y, et al. Rapamycin for lymphangioleiomyomatosis: optimal timing and optimal dosage. Thorax 2018; 73: 308-310.

146 Maisel K, Merrilees MJ, Atochina-Vasserman EN, et al. Immune checkpoint ligand PD-L1 is upregulated in pulmonary lymphangioleiomyomatosis. Am J Respir Cell Mol Biol 2018; 59: 723-732.

147 Pietrobon A, Delaney SP, Stanford WL. Could immunotherapy sink its teeth into lymphangioleiomyomatosis? Am J Respir Cell Mol Biol 2018; 59: 663-665.

148 Han F, Dellacecca ER, Barse LW, et al. Adoptive T-cell transfer to treat lymphangioleiomyomatosis. Am J Respir Cell Mol Biol 2020; 62: 793-804. 